\title{
Hearing between wor(l)ds: rhetorical space and disrupting narratives in medicine
}

\author{
Cite as: CMAJ 2017 December 4;189:E1494-6. doi: 10.1503/cmaj.170744
}

\begin{abstract}
Are you allowed to have favourites, in research? Nico was one of mine: an articulate, charming, well-dressed young man whose self-possession and definitive words belied a tendency for nervous laughter. I wasn't sure what to expect on our first meeting. His case manager had simply said, "Oh yeah, he likes to talk," when I was recruiting participants for a narrative project in one of Toronto's first-episode psychosis clinics. When Nico showed up at my office, his presence commanded attention. He had a story to tell, and it was compelling.
\end{abstract}

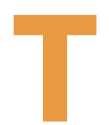

he term "narrative competence" is widely used within the narrative medicine literature, particularly that which relates to medical education. It makes reference to the capacities, attitudes and skills that one (learners especially) ought to demonstrate if one is to be able to absorb, interpret and act on the stories that are heard in clinical practice. ${ }^{1}$ That said, the term has been criticized for its emphasis on the centrality of the medical professional, as well as the notion that mere "competence" (i.e., passable efficiency in an area) is sufficient. In this case, I use the term (not unreflexively) to gesture toward a body of literature in which I am attempting to intervene. Narrative competence has been described by health humanities scholars as a critical capability in medical education and an important component of empathic engagement, as well as diagnostic reasoning. ${ }^{1}$ As Miriam Solomon has argued, this isn't merely a matter of adding some "humanity" or "art" to the science of medicine; learning narrative theory is one of a set of cognitive techniques that is pertinent across scientific disciplines. ${ }^{2}$ The breadth of discussion and the popularity of narrativity in medical education and clinical practice reflect, perhaps, an exuberance for the wider narrative turn that has occurred in a range of social sciences. ${ }^{3}$

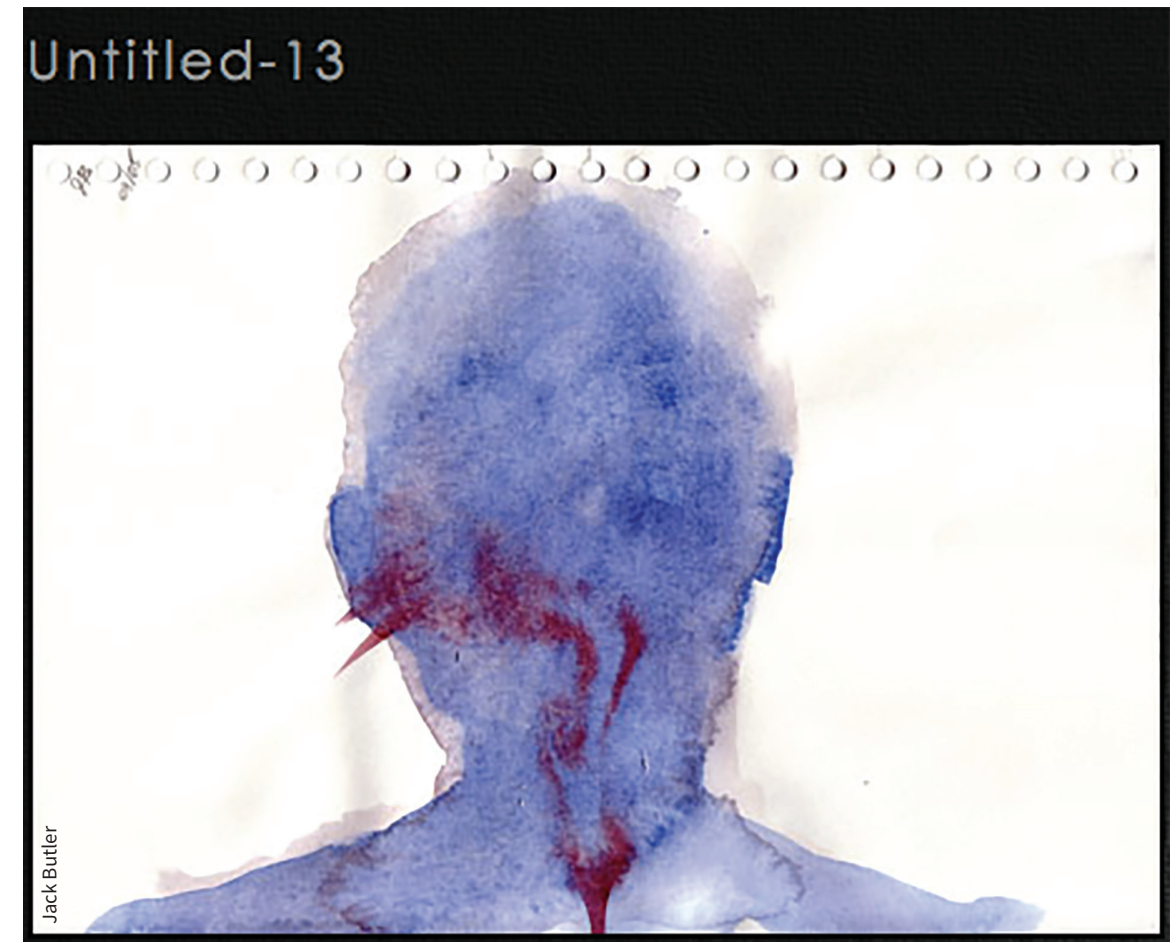

Despite connections to literary theory, narrative studies and social research, a limited number of the critical analyses surrounding narrative in these domains have made their way into the purview of medicine, medical education especially. If, as Alan Bleakley has suggested, we need to enhance the capacity of learners to do more than "translate the patients' stories they hear into ... an aural equivalent of the objectifying medical gaze," attending to the problematizations, appraisals and critiques of stories (and their uses) that circulate outside of medically oriented scholarship is of importance. Mobilizing reflections on my research encounters with Nico (as in the epigraph above), I probe what it means for experience to be turned into "matters of fact," reflecting critically on the direc- tions that narrative medicine might embrace if it is to move toward a more questioning engagement with "the social, political and historical dynamics" of human experience. ${ }^{3}$

\section{Nico's story}

An extrovert, Nico displayed a lovely kind of confidence when taking his space in the consulting room. I had hardly finished introducing myself when his story came pouring out. He had come to Canada as a refugee during his late teens, persecuted for his sexual identity. His psychosis was intertwined with his religious upbringing; he had believed for many years that the hallucinations reflected god's need to punish him. In that first meeting, he spoke about how, over time, his friends and his mental health team gently challenged his beliefs, enabling him to embrace a biomedical view of psychosis as one that just made "sense." Taking antipsychotic medications 
helped him "slow down" and "be rational." It was through this process that he had come to a place of understanding and acceptance of himself.

But as I sat across from him, I couldn't help but think, "something is missing." There was a gap in his story. Although the overall temporality of his narrative was linear, something was missing in the spaces between the words something that left me unsettled as I listened.

It would have been easy to adopt Nico's first telling of his story. Rather than illness as a kind of spiritual quest, his was one of healing as an embrace of science and the rational-technical expertise of biomedicine: it rang with the kind of "insight" that a clinician (especially) wants to hear. There was truth in its telling, to be sure. But I experienced dissonance as Nico smoothly slid over parts of his story. Some stories remain "unheard" when they don't fit the narrative parameters of a given context; ${ }^{5}$ in this instance, something was left unheard because the story fit too easily into the context of the first-episode clinic

\section{Rhetorical space}

Nico seems to struggle a bit as I probe about what it was like to take the antipsychotic medication. We had danced back and forth during that first interview, trying both to articulate and hear what had to have taken place for him to leave behind his spiritual practice, his religious beliefs and aspects of his family and culture. But it isn't until our second meeting that he is able to dive back into the years of ambivalence about medications, the tensions between him and his health care team, the vivid, visceral reality of hallucinations and tactile sensations. It's only now that I hear the agony of the experience without the polish of an enlightenment quest narrative.

As the more complex truths of Nico's story unfolded in subsequent interviews, I looked to philosopher Lorraine Code to understand what was taking place. Code introduces the concept of "rhetorical space" to refer to the sociocultural and material geography of communicative events. Such geographies determine the very possibility of accepting utterances

\section{But as I sat across from him, I couldn't help but think, "something is missing."}

and the biomedical frame provided by the hospital setting. Ultimately, this was a result of other truths that had been left unsaid. Missing these truths would have limited the quality and validity of my research; in a clinical setting, this could have substantial consequences for therapeutic alliance and Nico's engagement in mental health care.

Current iterations of narrative medicine call for a dialogical attitude toward narrative if the story is to be more than merely an extension of the stethoscope. ${ }^{4,6}$ In the dialogical frame, one does not treat a given story as though it were data to be mined ${ }^{5}$ and the storyteller is not finalized in the uptake of their narrative. ${ }^{5}$ But just how far does a dialogical approach get us? I puzzled over this in my attempts to understand the signal that there was more to Nico's story than its first telling suggested. and experiences. Certain truths will simply not be spoken or heard in particular locations. ${ }^{7}$ Similarly, what can be said in a given space depends to a great degree on who counts as believable within that location. ${ }^{7}$ In essence, it was in attending to the rhetorical space of the interviews that I recognized the premature finalization of Nico's story through the template of a progress narrative. This recognition enabled a more adequate engagement with what could be said and not said, drawing out the nonconforming aspects of Nico's story.

His story was responsive to the frame of our encounter: the hospital setting, the clinical office in which we met, my role as a psychiatric helping professional, his role as "patient," and to our respective social positions (him: a young, gay man, visible minority and refugee, precariously housed; me: white, settler, educated, upper middle class professional trainee with no obvious stigmata of disability). The demarcation of physician from patient (or researcher from participant) has a spatializing function that is imbued with rhetorical significance. This determines who will divulge subjective experience and behaviours, versus who will define, categorize and code those experiences according to normative definitions. For Nico and I, this shaped what had initially remained in the spaces between the words.

The notion of rhetorical space is instructive and pushes beyond a dialogical approach to narrative: even as dialogical approaches consider social and relational factors such as the self-identity of interlocuters and the reasons for offering a particular story at a given time, much focus continues to be placed on the individual storyteller, listener and the text itself. Rhetorical space asks us to look outside the narrative frame, to a wider social, cultural and historical context. With Nico, it was in attending to our intersectionalities, as well as to the sociohistorical and political context in which we had come together, that a different kind of telling and hearing was possible. This context includes the technical-rational framework of medicine as a whole, which tends to diminish the ability of many service users to claim status as knowers (particularly true when they offer a counternarrative to the dominant view in the rhetorical space of medical practices). Failing to attend to rhetorical space contributes to the view that stories are valuable merely for the raw data they might provide and toward the tendency to have certain narratives propagated, lauded and co-opted for their capacity to enhance the status quo. ${ }^{8}$

\section{Critical interventions}

Appreciating the rhetorical gatekeeping that was occurring in my encounters with Nico, I was able to hear both what could be said and not said. Because power shapes the rhetorical space of clinical encounters, critically engaging with this is a necessary component of narrative medicine. This insight moves us away from the classical (structuralist) view of narratology, with its emphasis on concepts and 
categories that could be applied universally to narratives, regardless of how they were produced or where they came from. ${ }^{9}$ As feminist, queer and postcolonial interventions in narrative studies have argued (and as my use of "rhetorical space" suggests), narrative form and content are inseparable from the broader context in which texts are written, distributed and responded to. ${ }^{10}$ These interventions in narrative studies likewise look to the intersectional dimensions of identity in shaping and understanding how stories are produced and how they are taken up and hold issues such as temporality, spatiality and performativity to be central. ${ }^{9}$

Delese Wear and Julie Aultman have argued that a major limitation of narrative medicine (extending into medical education especially) has been its almost exclusive reliance on exchanges between individual entities (storytellers, patients and texts) and the resulting lack of attention to social structures. ${ }^{11}$ There is a wealth of resources within contemporary narrative studies for disrupting the telling of stories that merely reflect back the hierarchies and normativities that narrative competence hopes to overcome. Might this kind of narrativity make for better listening and for better medicine?

\section{Suze Berkhout MD PhD}

Department of Psychiatry, University of Toronto, Toronto, Ont.

\section{References}

1. Charon R. The patient-physician relationship. Narrative medicine: a model for empathy, reflection, profession, and trust. JAMA 2001;286:1897-902.

2. Solomon M. Epistemological reflections on the art of medicine and narrative medicine. Perspect Biol Med 2008;51:406-17.
3. Goodson IF, Gill SR. The narrative turn in social research. Counterpoints 2011;386:17-33.

4. Bleakley A. Stories as data, data as stories: making sense of narrative inquiry in clinical education. Med Educ 2005;39:534-40.

5. Frank A. Letting stories breathe: a socio-narratology. Chicago: The University of Chicago Press; 2010.

6. Frank A. Practicing dialogical narrative analysis. In: Varieties of Narrative Analysis. Holstein J, Gubrium J, editors. Los Angeles: Sage Press; 2012:33-52.

7. Code L. Rhetorical spaces: essays on gendered locations. New York: Routledge; 1995.

8. Costa L, Voronka J, Landry D, et al. Recovering our stories: a small act of resistance. Stud Soc Justice 2012;6:85-101.

9. Warhol R, Lanser S, editors. Narrative theory unbound: queer and feminist interventions. Columbus (OH): The Ohio State University Press; 2015.

10. Gymnich M. Gender and narratology. Literature Compass 2013;10:705-15.

11. Wear D, Aultman JM. The limits of narrative: medical student resistance to confronting inequality and oppression in literature and beyond. Med Educ 2005;39:1056-65.

This article has been peer reviewed.

The author has obtained patient consent. 